\title{
Syntheses and Crystal Structure of Zinc(II) Complex Constructed from taurine Schiff Base \\ Liyan You ${ }^{1, a}$, Hui Jiang ${ }^{1, b}$ and Chaohong $\mathrm{Ma}^{1, \mathrm{c}}$ \\ ${ }^{1}$ School of Arts and Science, Jilin Agricultural Science and Technology University, Jilin 132101, China \\ ayly5466@163.com, ㅎ983318@qq.com, 5533329347@qq.com
}

Keywords: Schiff Base; complex; crystal structure; Zinc

Abstract: The complex $\left[\mathrm{Zn}\left(\mathrm{C}_{8} \mathrm{H}_{9} \mathrm{~N}_{2} \mathrm{O}_{3} \mathrm{~S}\right)\left(\mathrm{C}_{8} \mathrm{H}_{6} \mathrm{O}_{5}\right)\left(\mathrm{H}_{2} \mathrm{O}\right)\right]\left(\mathrm{C}_{8} \mathrm{H}_{9} \mathrm{~N}_{2} \mathrm{O}_{3} \mathrm{~S}=\right.$ the Schiff base formed by 2-Pyridinecarboxaldehyde and taurine) was synthesized by reaction of $\mathrm{Zn}\left(\mathrm{CH}_{3} \mathrm{COO}\right)_{2} \cdot 2 \mathrm{H}_{2} \mathrm{O}$. The crystal structure of the Zinc(II) complex has been determined and studied by X-ray diffraction. The complex is monoclinic, space group $P 2(1) / c$, with $a=10.184(1) \AA, \quad b=9.571(2) \AA, \quad c=11.637(8) \AA, \alpha=81.91(9)$, $\beta=85.23(4), \gamma=78.56(9)^{\circ}, V=1134.27$ (6) $\AA^{3}, Z=1$. The asymmetric unit is comprised of a coordinaton cation together with a mononuclear coordination anion and two water molecules, all of which are linked by hydrogen bonding and $\pi-\pi$ interactions into a three-dimensional framework.

\section{Introduction}

Taurine is a kind of beta amino acids, which is containing sulfur group. Its unique physiological and pharmacological functions determine its wide application in medicine, food, chemical industry and so on. Schiff base and its complexes have good biological activity, and are attractive to researchers for their attractive prospects in catalysis, biological simulation and analytical chemistry.

In recent years, transition metal complexes of sulfur Schiff base have become one of the focuses for the good antitumor, antibacterial and other physiological activities and catalytic activity.In living organisms, the trace elements, such as, copper and nickel, often in high concentration of biological ligands in the environment, often with more than two kinds of biological ligands to form complexes, plays an important role in catalysis, material transfer process of these complexes in the life process of the enzyme and the storage and transport of metal ions.

Schiff base is a kind of important biological ligand that contains many coordination atoms. The transition metal complexes of Schiff base are similar to macrocyclic ligands. The biological activities of complexes of Schiff base, such as carrying oxygen, antibacterial and good catalytic performance, which has important significance in the fields of biology and medicine, has attracted the interest of researchers. The synthesis of transition metal complexes of Schiff base by traditional chemical methods has been reported, but the yield is not high and the process is complicated. The transition metal Schiff base complexes with friendly environment, high yield, simple operation and one-step synthesis have been shown to be of high value in theory and application, and have always been the synthetic direction that people have been trying to develop.

\section{Experimental}

\section{Materials and physical measurements}

All solvents and chemicals purchased from commercial sources were of reagent grade and used without further purification. IR spectra were performed on a Shimizu spectrum FT-IR spectrometer with $\mathrm{KBr}$ pallets in the range of $4000 \sim 400 \mathrm{~cm}^{-1}$. The elemental analyses for $\mathrm{C}, \mathrm{H}, \mathrm{N}$ and $\mathrm{S}$ were carried out on a Leeman elemental analyzer. The crystal data were collected on a Rigaku Xtalab area detector diffractometer at room temperature.

\section{Synthesis of the ligand $(L)$}

The ligand (L) was prepared as previously reported. 2-Pyridinecarboxaldehyde (10mmol, $1.071 \mathrm{~g}$ ) was 
dissolved in $10 \mathrm{~mL}$ absolute methanol, followed by dropping a solvent of taurine (10mmol, $1.251 \mathrm{~g})$ and potassium hydroxide $(10 \mathrm{mmol}, 0.561 \mathrm{~g})$ in absolute methanol solution $(30 \mathrm{~mL})$, and then the mixture was stirred at room temperature. After 2 hours' reaction, a large amount of yellow deposition was generated. After vacuum filtration, the residues were washed with the absolute ethanol $5 \mathrm{~mL}$ twice, and anhydrous ether $5 \mathrm{~mL}$ twice. The wet product was dried by vacuum oven, yielding the yellow power compound $\left(\mathrm{H}_{2} \mathrm{~L}\right)$. Yield: 71.3\%. Anal. Calcd. (\%) for $\mathrm{C}_{8} \mathrm{H}_{9} \mathrm{NO}_{3} \mathrm{SK}: \mathrm{C} 30.09$, H 3. 57, N 12. 14, S 12. 56; Found(\%): C 31. 15, H 3. 35, N 11. 93, S 12.87。

\section{Synthesis of complex1}

an aqueous solution containing $(5 \mathrm{~mL})$ Zinc acetate dehydrate $(1 \mathrm{mmol}, 0.220 \mathrm{~g})$ was added to the $\mathrm{H}_{2} \mathrm{~L}$ $(1 \mathrm{mmol}, 0.253 \mathrm{~g})$ aqueous solution $(10 \mathrm{~mL})$ with the proportion of methe $50 \%$. It takes 2 hours to reaction at the room temperature, then dropped the methanol solvent $(5 \mathrm{~mL})$ of 3,5-dihydroxybenzoic acid (1mmol, $0.154 \mathrm{~g}$ ). After stirring for $2 \mathrm{~h}$, the resulting solution was kept at room temperature by slow evaporation for about 9 days, yielding colorless square single crystals. Yield: $36 \%$.Selected IR data $\left(\mathrm{cm}_{-1}\right):(\mathrm{S}=\mathrm{O}) 1256.5$ cm-1 and $1131.1 \mathrm{~cm}_{-1},(\mathrm{~S}-\mathrm{O}) 998.2 \mathrm{~cm}-1$ and $(\mathrm{C}=\mathrm{N}) 1608.5 \mathrm{~cm}-1$. Anal. Calcd. (\%) for $\mathrm{C}_{16} \mathrm{H}_{17} \mathrm{ZnN}_{2} \mathrm{O}_{9} \mathrm{~S}$ : $\mathrm{C}$, 46.08; H, 2.68; N, 4.13; S, 9.46. Found (\%): C, 46.11; H, 2.66; N, 4.11; S, 9.48.

\section{Structure determination}

A suitable single crystal of complex $1(0.36 \mathrm{~mm} \times 0.24 \mathrm{~mm} \times 0.11 \mathrm{~mm})$ was selected and glued on the tip of a glass fiber. The crystal structure was determined at $298 \mathrm{~K}$ on an X-ray diffractometer, a Rigaku Xtalab detector diffractometer by using a $\mathrm{Cu} K \alpha$ radiation $(\lambda=0.154 \AA)$. All structures were solved using direct methods with SHELXS and refined by full-matrix leastsquares on $F_{2}$ using the SHELXL14 software within OLEX2. All the non-hydrogen atoms were refined anisotropically with displacement parameters. The hydrogen atoms were generated geometrically and treated by a mixture of independent and constrained refinement using a riding model. Crystal data and structure parameters for the title complex are listed in Table 1.

Table 1 Crystal data for Zinc(II) Compound

\begin{tabular}{ll}
\hline Polymers & Complex 1 \\
\hline Formula & $\mathrm{C}_{16} \mathrm{H}_{17} \mathrm{ZnN}_{2} \mathrm{O}_{9} \mathrm{~S}$ \\
Formula weight & 478.52 \\
Temperature(K) & 298 \\
Wavelength(A) & 0.154 \\
Crystal sizes(mm) & $0.36 \mathrm{~mm} \times 0.24 \mathrm{~mm} \times 0.11 \mathrm{~mm}$ \\
Color & colorless \\
Crystal system & monoclinic \\
Spaces group & P2(1)/c \\
a(A) & $10.184(1)$ \\
b(A) & $9.571(2)$ \\
$c(A)$ & $11.637(8)$ \\
\hline
\end{tabular}

Table 2 elected Bonds Lengths (nm) and Bonds Angles( $\left(^{\circ}\right)$

\begin{tabular}{ll|ll|ll|ll}
\hline \multicolumn{4}{c|}{ Bond Lengths } & \multicolumn{4}{c}{ Bond Angles } \\
\hline Zn1-O1w & $1.925(1)$ & C1-N1 & $1.316(2)$ & O6-Zn1-O1w 90.3(1) & C1-N1-C5 & $101.9(5)$ \\
Zn1-O6 & $1.924(4)$ & C7-N2 & $1.567(1)$ & N2-Zn1-O1w 98.4(5) & N1-C1-C2 & $106.3(5)$ \\
Zn1-N1 & $1.851(7)$ & C6-N2 & $1.339(6)$ & N1-Zn1-N2 & $83.7(2)$ & N1-C5-C6 & $110.4(1)$ \\
Zn1-N2 & $2.012(3)$ & C5-N1 & $1.326(2)$ & O6-Zn1-N1 & $86.9(6)$ & C6-N2-Zn1 & $118.9(1)$ \\
Zn1-N1 & $1.845(6)$ & S1-O1 & $1.354(5)$ & O1-S1-O2 & $112.3(2)$ & C10-C9-O6 & $115.6(3)$ \\
Zn1-N2 & $1.672(5)$ & S1-O2 & $1.376(2)$ & O1-S1-O3 & $114.2(8)$ & C9-06-Zn1 & $109.6(7)$ \\
& & S1-O3 & $1.315(1)$ & O2-S1-O3 & $111.7(4)$ & O7-C9-O6 & $118.6(2)$ \\
\hline
\end{tabular}


Symmetry transformations used to generate equivalent atoms: \#1:- $\mathrm{x}+1,-\mathrm{y}+1,-\mathrm{z}+1$

\section{Results and Discussion}

\section{Structural Description}

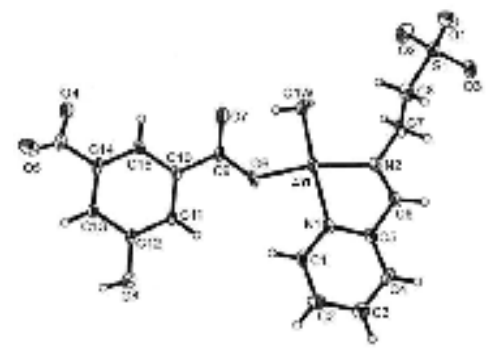

Fig.1 Crystal Structure of complex1 $\left[\mathrm{Zn}\left(\mathrm{C}_{8} \mathrm{H}_{9} \mathrm{~N}_{2} \mathrm{O}_{3} \mathrm{~S}\right)\left(\mathrm{C}_{8} \mathrm{H}_{6} \mathrm{O}_{5}\right)\left(\mathrm{H}_{2} \mathrm{O}\right)\right]$

$\mathrm{X}$-ray diffraction results show that crystal structure of the complex1. It indicates the central Zinc (II) coordinates two atoms of $\mathrm{N}(\mathrm{N} 1$ and N 2) from Schiff base L respectively, oxygen(O6) from the carboxyl of 5-Hydroxyisophthalic acid, and oxygen $(\mathrm{O} 1 \mathrm{w})$ from water. The coordination modes and structural topologies give rise to some valuable information. As shown in Fig1, four coordination atoms, N1, N2, O6 and O1W are almost in the same plane. The angles of the four atoms are O6-Zn1-O1W 90.3(1) ${ }^{\circ}$, O1W -Zn1-N2 98.4(5) ${ }^{\circ}, \mathrm{N} 2-\mathrm{Zn} 1-\mathrm{N} 1$ $83.7(2)^{\circ}, \mathrm{N} 1-\mathrm{Zn} 1-\mathrm{O} 686.9(6)^{\circ}$. The sum of the four angles nearly $359.3^{\circ}$, which reveals that coordinated atoms in the same plane.

\section{IR Analysis}

The infrared spectra of ligands and coordination polymers were determined by the potassium bromide tabletting method in the range of $4000-400 \mathrm{~cm}^{-1}$ wavenumbers. There are strong peaks which were found near the $1621 \mathrm{~cm}^{-1}$. It indicates the formation of $\mathrm{C}=\mathrm{N}$ Schiff base. The absorption peaks of $1189 \mathrm{~cm}^{-1}$ and $1008 \mathrm{~cm}^{-1}$ are characteristic absorption peaks of sulfonic group. We also find absorption peaks at $1294 \mathrm{~cm}^{-1}$ which belong to C $\mathrm{O}$ of phenol oxygen. The absorption peak at $1442 \mathrm{~cm}$ belongs to the benzene. The absorption peaks found around $831 \mathrm{~cm}^{-1}$ and $738 \mathrm{~cm}^{-1}$ belong to the characteristic absorption peaks of pyridine. It is obviously that -OH stretching frequency of water molecules coordinate because of the presence of the broad band around $3430 \mathrm{~cm}^{-1}$.Comparison with the infrared spectra of the ligand and the synthesized Zinc complex, it makes clear that the coordination bonds have formed.

\section{Thermal Stability Behavior}

In order to discuss the thermal stability of the Zinc complex, the thermogravimetric analysis of the Zinc complex is carried out under conditions of temperature with the increasing rate $10^{\circ} \mathrm{C} / \mathrm{min}$, from $25^{\circ} \mathrm{C}$ to $450^{\circ} \mathrm{C}$. There are two steps of the decomposing. Thermal analysis of complex shows that the weight loss starts at $56-66^{\circ} \mathrm{C}$, the total loss of $3.607 \%$ attributed to the release of $\mathrm{H}_{2} \mathrm{O}$, which is calculated $3.762 \%$. The exquisite weight loss appears at $346-389^{\circ} \mathrm{C}$, which is attributing to the decomposing of the Schiff base. The final resides is comparing with other complexes which are depending on the bridging ligands, the network structure constructing with chelating ligands is relatively unstable. 


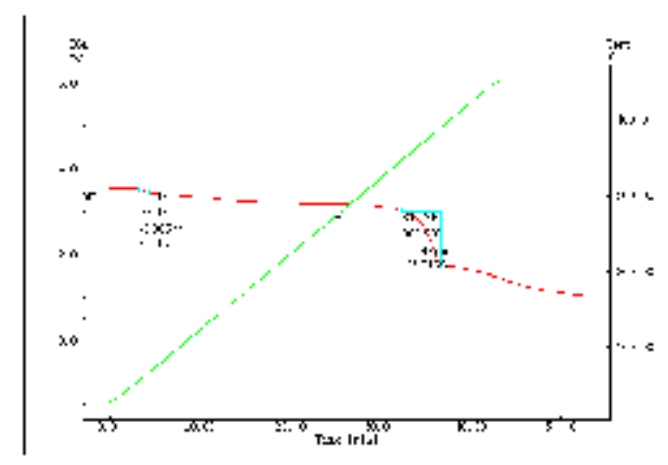

Fig.2 The thermogravimetric analysis of the Zinc complex

\section{Conclusions}

In this paper, we have presented the $\mathrm{Zinc}(\mathrm{II})$ complex $\left[\mathrm{Zn}\left(\mathrm{C}_{8} \mathrm{H}_{9} \mathrm{~N}_{2} \mathrm{O}_{3} \mathrm{~S}\right)\left(\mathrm{C}_{8} \mathrm{H}_{6} \mathrm{O}_{5}\right)\left(\mathrm{H}_{2} \mathrm{O}\right)\right]\left(\mathrm{C}_{8} \mathrm{H}_{9} \mathrm{~N}_{2} \mathrm{O}_{3} \mathrm{~S}=\right.$ the Schiff base synthesized by 2-Pyridinecarboxaldehyde and taurine).The crystal structure of the Zinc (II) complex has been determined and studied by X-ray diffraction, which is also characterized by elemental analysis, IR spectra. Thermogravimetric analysis also has been studied in order to investigate the thermol behavior carefully.

\section{Acknowledgements}

This work was supported by Foundation of Jilin Educational Committee ([2015]377); Science and Technology Development Funds of Jilin city (20156431); and Youth Foundation of Jilin Agricultural Science and Technology University ([2014]209).

\section{References}

[1] Y. Kato, M. Furutachi, Z. Chen, H. Mitsunuma, S. Matsunaga. A Homodinuclear Mn(III) 2-Schiff Base Complex for Catalytic Asymmetric 1,4-Additions of Oxindoles to Nitroalkenes.

J. Am. Chem. Soc.. 2009, 131 (26): p9168-9169.

[2] Z. Tang, X. Chen, X. Pang, Y. K. Yang, X. F. Zhang, X. B. Jing. Stereoselective Polymerization of rac-Lactide Using a Monoethylaluminum Schiff Base Complex. Biomacromolecules. 2004, 5 (3): p965-970.

[3] R.Corriu , E. Lancelle-Beltran , A. Mehdi , C. Reyé , S. Brandès. Ordered mesoporous hybrid materials containing cobalt(II) Schiff base complex. 2002, 12(5):p1355-1362

[4] A.H. Kianfar , A.K.M. Wan , M. Dinari , M.H. Azarian , F.Z. Khafri. Novel nanohybrids of cobalt(III) Schiff base complexes and clay: Synthesis and structural determinations. Spectrochimica Acta Part A: Molecular and Biomolecular Spectroscopy. 2014, 127(1644): p422-428

[5]G. M. Sheldrick, SHELX-97, Program for the solution and Refinement of Crystal Structures. University of Gottingen: Gottingen, Germany, (1997).

[6] J. O. Yu, A. P. Côté, G. D. Enright, G. K. H. Shimizu. The First Nonlayered Metal Sulfonate Structure: a 1-D $\mathrm{Ba}^{2+}$ Network Incorporating Hydrophobic Channels. Inorganic Chemistry, 2001, 40 (4), p582-583. 